\title{
NEGATIVE GOLD STAINING FOR ELEGTROPHORETIG PROTEIN PROFILE INTERPRETATIONS
}

\author{
Bruge BUDOWLE and Anne M. GAMBEL
}

\author{
Forensic Science Research and Training Center Laboratory Division, FBI Academy, \\ Quantico, Virginia 22135, USA
}

\begin{abstract}
A simple method was described for negative gold staining of ultrathinlayer polyacrylamide gels. The protein bands were clear (unstained) and sharp while the gel matrix was pink-purple. Negative gold staining was up to five-fold more sensitive than coomassie blue, but an order of magnitude less sensitive than silver staining for protein detection. However, there were examples where negative gold staining was able to detect particular proteins not effectively stained by coomassie blue or silver.
\end{abstract}

Since most proteins are colorless, protein detection methods are necessary to enable their visualization after electrophoretic separation. Organic dyes such as bromophenol blue (11), amido black (16) and coomassie blue (CB) (13) are generally used for protein staining. Coomassie blue, with its capability of detecting as little as $0.1 \mu \mathrm{g}$ of protein, is the most sensitive of the organic dyes. The introduction of silver as a general protein stain increased the sensitivity of protein detection 100-500fold over that attained with $\mathrm{CB}(1,2,5,8,14,22,23,25,28,31,34,37,39,40)$. Although silver is a more sensitive protein stain than $\mathrm{CB}$, there are examples in the literature of proteins that can be stained by CB and not silver $(12,19,24,32)$. This phenomenon is due to different staining mechanisms of CB and silver and the molar ratios of basic and sulfur-containing amino acids of the particular proteins $(24,25)$. Additional stains, particularly with different staining mechanisms, may make it possible to visualize proteins that are not readily detectable with $\mathrm{CB}$ or silver. Recently, colloidal gold bound to immunoglobulins, lectins and protein $\mathrm{A}$ has been employed for detection of specific sites in histological preparations $(10,17,18,29,30)$. In addition, gold staining has been used by Brada and Roth (3) and Moeremans et al. $(26,27)$ for staining protein blots on nitrocellulose membranes. We sought to apply gold staining methodology to general protein profile detection after polyacrylamide gel electrophoresis or agarose gel electrophoresis. However, this approach was not adaptable to polyacrylamide or agarose (Budowle, unpublished data). While we were investigating gold staining, Casero et al. (9) reported a negative gold staining procedure for protein detection in polyacrylamide gels that appeared promising. This paper presents modifications of the negative gold staining procedure which yield increased sensitivity of protein detection as well as band intensity and demonstrates specific applications for electrophoretic protein pattern interpretation. 


\section{MATERIALS AND METHODS}

Transferrin (Tf) from plasma and bloodstains was subtyped by ultrathin-layer polyacrylamide gel isoelectric focusing (ULPAGIF), as previously described $(6,8)$. Alpha 1-antitrypsin ( $\mathrm{Pi}$ ) from plasma was subtyped by ULPAGIF using Servalyte $\mathrm{pH} 4-5$ according to the method of Budowle and Murch (7). Various dilutions of carbonic anhydrase (CA) (Sigma) and bovine serum albumin (BSA) (Sigma) were subjected to ULPAGIF using Ampholines pH 3-10 (LKB) with running conditions previously described (7).

Negative gold staining was performed according to a modified procedure of Casero et al. (9). After ULPAGIF the gels were fixed in a solution containing $5 \%$ trichloroacetic acid, 5\% copper sulfate and $0.35 \%$ sulfosalicylic acid for $25 \mathrm{~min}$ with continuous agitation. Next, the gels were washed in distilled water for $30 \mathrm{~min}$. The gels were placed in plastic bags containing gold solution, sealed and incubated overnight in the dark at room temperature with continuous agitation. The gold stain was prepared in a $0.1 \%(\mathrm{v} / \mathrm{v})$ Tween 20 and $0.19 \%(\mathrm{w} / \mathrm{v})$ citric acid solution. Immediately prior to use, chloroauric acid (HAuC14) (Sigma) was added to the solution to a final concentration of $0.01 \%(\mathrm{w} / \mathrm{v})$. After gold staining, the gels were placed in water and the gel surface was gently wiped with a wet cotton swab or kim wipe to remove precipitated gold. The gels were then washed in $1 \%(\mathrm{v} / \mathrm{v})$ glycerol for $15 \mathrm{~min}$ and air dried. Coomassie blue staining was performed, as previously described (4), and silver staining was performed according to Budowle and Scott (8).

\section{RESULTS AND DISGUSSION}

The gold stain yielded protein zones that were clear and in sharp contrast to a pink-purple background. Since the proteins were colorless, the stain was referred to as negative gold stain. The major differences between the negative gold stain used in this paper and that reported by Casero et al. (9) were the use of copper sulfate instead of zinc sulfate during fixation and the addition of gold chloride to the stain solution immediately prior to staining the gels. Fig. 1 clearly shows that copper sulfate treated gels produced a more intense negative protein pattern for CA than did zinc sulfate treated gels. Further, the use of freshly-prepared gold solutions (instead of solutions incubating for two hr prior to use) also improved pattern intensity (Fig. 2). The same trends were observed for BSA and general plasma protein profiles. Varying amounts of BSA and CA were applied to gels to compare the sensitivity of detection of negative gold staining with $\mathrm{CB}$ and silver stain. In general, negative gold staining was exhibited from equal to a five-fold increase in sensitivity for protein detection compared with $\mathrm{CB}$ (the lower limit of detection for $\mathrm{CB}$ was $100 \mathrm{ng}$ ). The silver stain method demonstrated an order of magnitude greater sensitivity than negative gold staining for protein detection.

Regardless of the above findings, there were a number of situations where negative gold staining detected proteins for which $\mathrm{CB}$ and silver staining were ineffective. Fig. 3-5 show plasma and bloodstain protein profiles stained with gold. The heterogeneous nature of Tf easily can be observed with negative gold staining (Fig. 3). Region I (the monoferric form of Tf) is the area of the gel normally used for determining the common allelic products of Tf-C1, C2 and C3 (15, 20, 21, 35). 


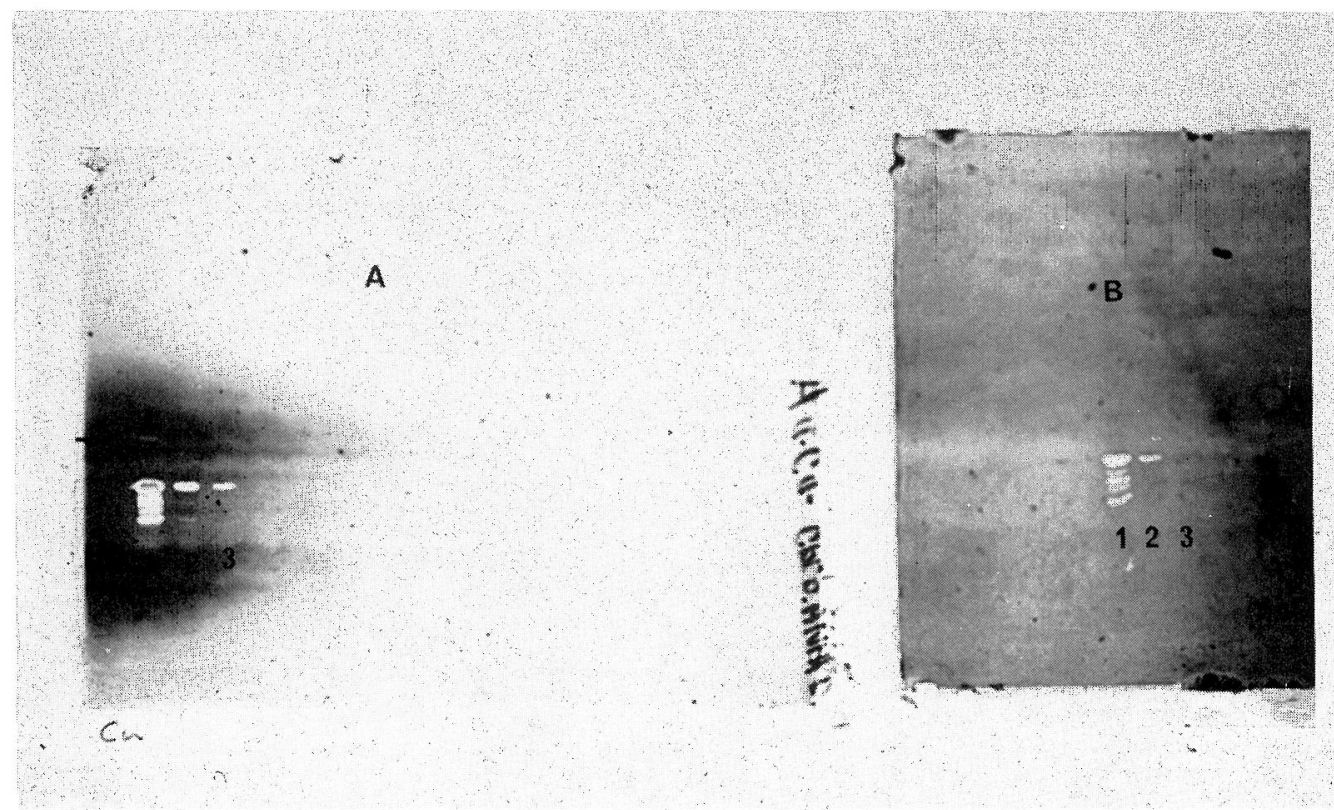

FIG. 1. A comparison of negative gold staining gels displaying CA. Gel A was pretreated with copper and gel B was pretreated with zinc. Samples 1.2 and 3 were $1000 \mathrm{ng}, 100 \mathrm{ng}$ and $50 \mathrm{ng}$ of CA, respectively.

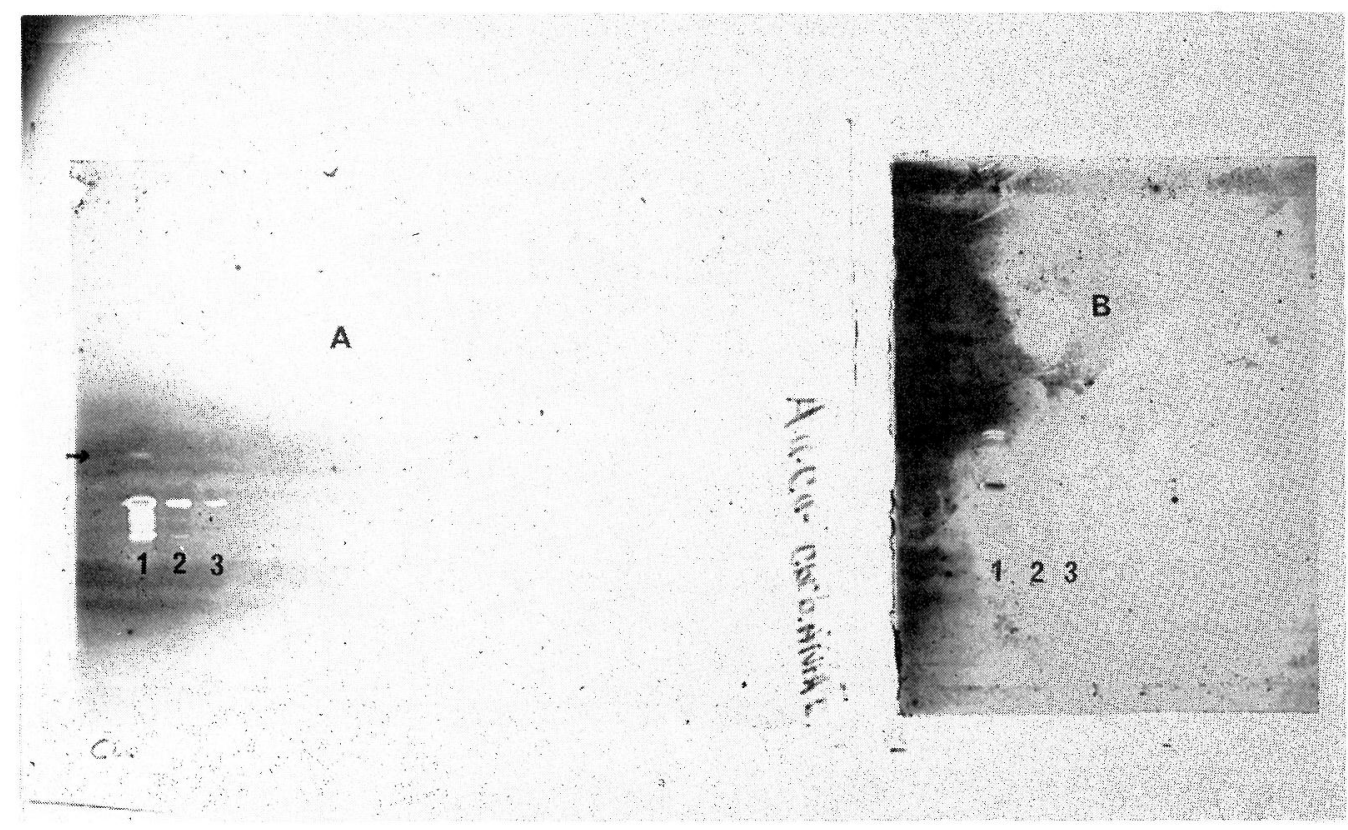

FIG. 2. A comparison of negative gold staining gels displaying CA. Gel A was stained with freshly prepared stain and gel B was stained with a stain that sat for two hr. Samples 1, 2 and 3 were $1000 \mathrm{ng}, 100 \mathrm{ng}$ and $50 \mathrm{ng}$ of CA, respectively. 
While silver and CB provided inadequate staining, negative gold staining produced intense staining for Tf in regions II and III (apoferric and desialated forms of Tf, respectively $(21,33,36,38)$. The $\mathrm{C} 1, \mathrm{C} 2$ and $\mathrm{C} 3$ allelic products could be resolved in regions $\mathrm{I}$ and II, and $\mathrm{C} 1$ and $\mathrm{C} 2$ could be resolved in region III. Thus, negative gold staining provided the capability of typing Tf in multiple regions in the gel.

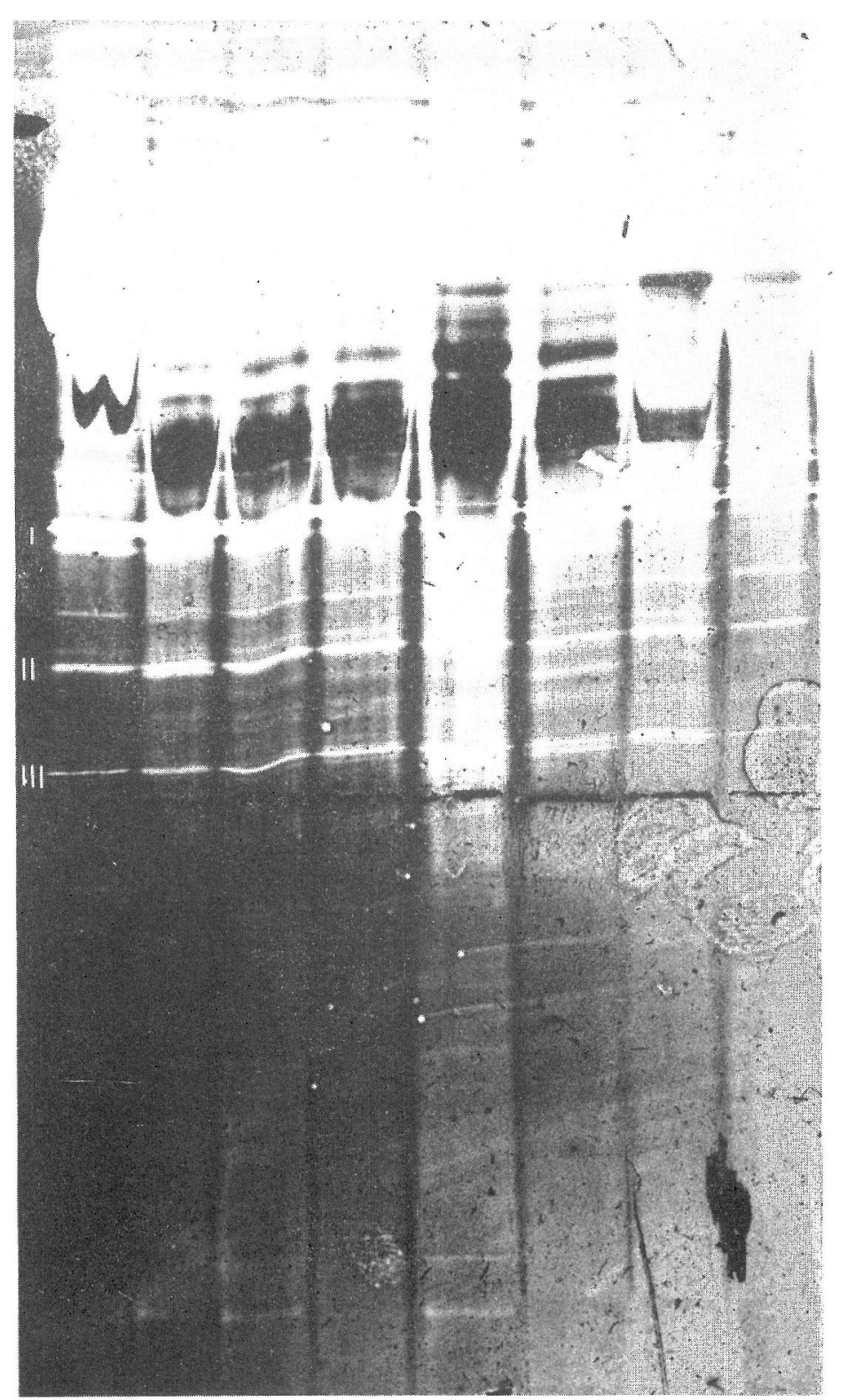

FIg. 3. Negative gold stained Tf from serum. Regions I, II and III are zones of Tf. Tf phenotypes from left to right are $\mathrm{C} 1, \mathrm{C} 1 \mathrm{C} 3, \mathrm{G} 1, \mathrm{G} 1, \mathrm{G} 1 \mathrm{C} 2, \mathrm{G} 1 \mathrm{C} 2, \mathrm{G} 1$ and $\mathrm{C} 1$. The anode is at the top. 


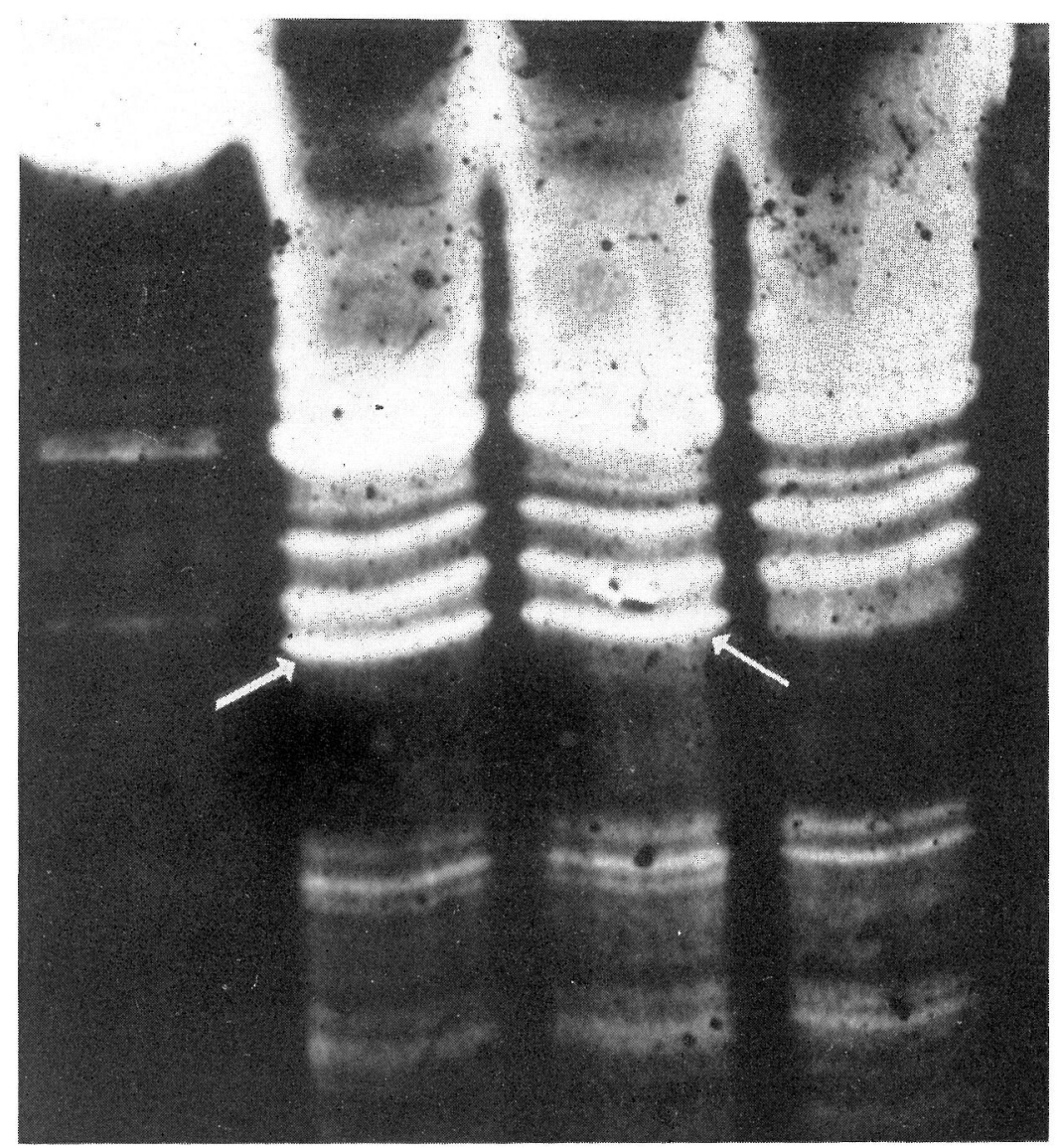

Frg. 4. Negative gold stained Tf from bloodstains. The arrows indicate the Tf $\mathrm{C} 2$ secondary band. The anode is at the top.

Transferrin phenotypes in bloodstains can be difficult to interpret without the identification of the Tf C2 secondary band (8). Using CB stain, this protein band could not be observed. This led Budowle and Scott (8) to employ silver staining to observe the Tf C2 secondary band. Even with silver staining, the Tf C2 secondary band does not stain as intensely as the other Tf allelic products. Thus, weak protein patterns at times can be difficult to interpret, resulting in inconclusive interpretations. As shown in Fig. 4, this problem can be overcome with negative gold staining which produced a Tf C2 secondary band with an intensity equal to the other Tf allelic products.

Fig. 4 is a negative gold stained gel displaying Pi subtypes. The arrow indicates a protein which migrated slightly anodal to the $\mathrm{S}$ band in the $\mathrm{M} 7$ region. This protein is nor $\mathrm{Pi}$ in origin (confirmed by immunofixation with antisera to $\mathrm{Pi}$ ). Neither GB nor silver could effectively stain this protein.

It was expected that silver, the most sensitive of stains, would detect proteins that neither $\mathrm{CB}$ nor gold could detect. The above data shows that negative gold 


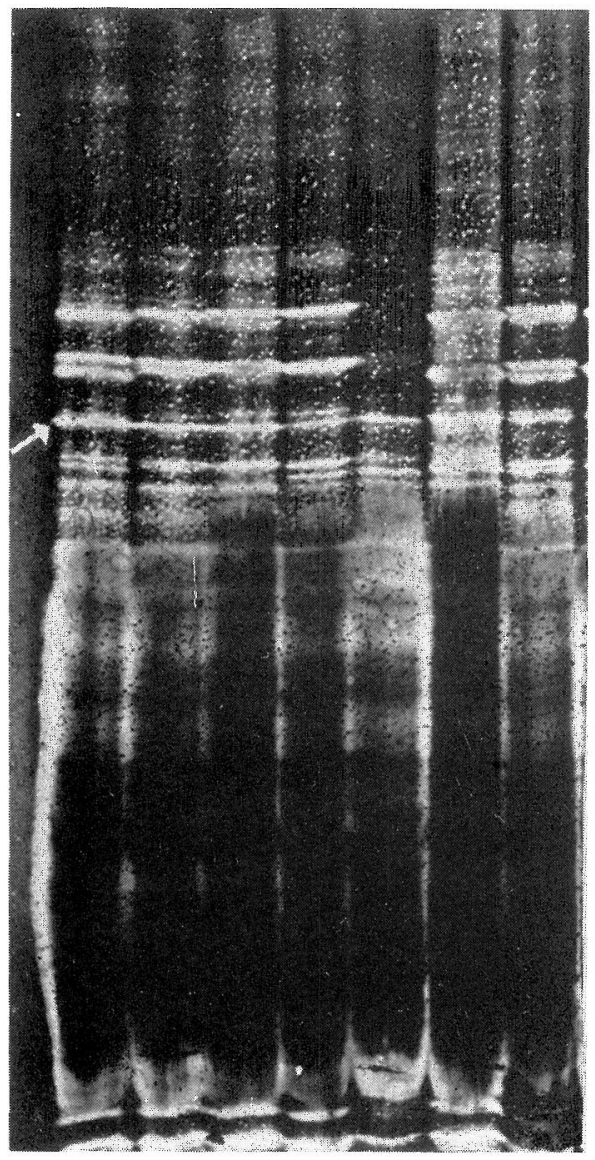

Fig. 5. Negative gold stained gel displaying Pi types. The arrow points to unknown protein that does not stain with $\mathrm{CB}$ or silver. The anode is at the top.

stain, although not as sensitive as silver, can be used to detect certain proteins that $\mathrm{CB}$ and silver are unable to stain. By using all three stains, $\mathrm{CB}$, silver, and gold, protein profiles can be more effectively interpreted in gels after electrophoresis. Elucidation of the negative gold staining mechanism will provide information about the structure of the proteins for which this stain has a particular affinity. However, at this time, the staining mechanism remains unclear. The copper (or zinc) cation dramatically increases the sensitivity and intensity of the stain over gels that are not pre-treated with copper sulfate stain. The positively charged gold micelle can diffuse into the gel matrix and possibly is repelled by the positively charged protein moieties (the positive charge of the protein due to the cation association). The result is a pink-purple stained gel matrix and clear, sharp protein bands.

In conclusion, a modification of the negative gold staining procedure of Casero et al. (9) providing greater sensitivity of protein detection has been described. Negative gold staining enabled the interpretation of certain proteins which were not effectively revealed by more conventional staining procedures. We presently are 
attempting to determine the negative gold staining mechanism using known amino acids and homopolymers of amino acids.

\section{DISGLAIMER}

This is publication number 86-8 of the Laboratory Division of the Federal Bureau of Investigation. Names of commercial manufacturers are provided for identification only, and inclusion does not imply endorsement by the Federal Bureau of Investigation.

\section{REFERENCES}

1. Allen, R. C.: Rapid isoelectric focusing and detection of nanogram amounts of proteins from body tissues and fluids. Electrophoresis 1; 32-37, 1980.

2. Allen, R. G., Saravis, C. and Maurer, H.: Component visualization. In Electrophoresis and Isoelectric Focusing of Proteins: Selected Techniques, ed. by R. C. Allen, C. Saravis and H. Maurer, Walter de Gruyter, Berlin, 1984, pp. 187-201.

3. Brada, D. and Roth, J.: Golden blot-detection of polyclonal and monoclonal antibodies bound to antigens on nitrocellulose by protein A-gold complexes. Anal. Biochem. 142; 79-83, 1984.

4. Budowle, B.: Increasing the sensitivity of detection of the electrophoretic marker group-specific component in agarose gels by double-staining with coomassie brilliant blue R250 and silver. $J$. For. Sci. 29; 1183-1186, 1984.

5. Budowle, B.: Increasing the sensitivity of protein detection of a silver stain for agarose gels. Electrophoresis 5; 174-175, 1984.

6. Budowle, B.: Transferrin subtypes determined by ultrathin-layer polyacrylamide gel isoelectric focusing. Electrophoresis 6, 97-99, 1985.

7. Budowle, B. and Murch, R. S.: A high resolution, rapid procedure for alpha 1-antitrypsin phenotyping. Electrophoresis 6, 523-525, 1985.

8. Budowle, B. and Scott, E.: Transferrin subtyping of human bloodstains. For. Sci. Int. 28; 269-275, 1985.

9. Casero, P., Campo, G. B. and Righetti, P. G.: Negative aurodye for polyacrylamide gels: The impossible stain. Electrophoresis 6; 367-372, 1985.

10. Danscher, G.: Localization of gold in biological tissue. Histochemistry 71; 81-88, 1981.

11. Durrum, E. L.: A microelectrophoretic and microionophoretic technique. Amer. Chem. Soc. 72; 2943-2948, 1950.

12. Dzandu, J. K., Deh, M. H., Barratt, D. L. and Wise, G. E.: Detection of erythrocyte membrane proteins, sialoglycoproteins and lipids in the same polyalcrylamide gel using a doublestaining technique. Proc. Natl. Acad. Sci. USA 81; 1733-1737, 1984.

13. Fazekas de St. Groth, S., Webster, R. G. and Datyner, A.: Two new staining procedures for quantitative estimation of proteins on electrophoretic strips. Biochem. Biophys. Acta 71; 377-391, 1963.

14. Fujita, K., Toda, T. and Ohashi, M.: Silver stain for proteins on a cellulose acetate membrane. Anal. Biochem. 139; 463-467, 1984.

15. Gorg, A., Weser, J., Westermeier, R., Postel, W., Weidinger, S., Patutschnick, W. and Cleve, H.: Isoelectric focusing with immobilized $\mathrm{pH}$ gradients for the analysis of transferrin (Tf) subtypes and variants. Hum. Genet. 64; 222-226, 1983.

16. Grassman, W. and Hannig, K. Z.: Physiol. Chem. 290; 1-27, 1952.

17. Holgate, C. S., Jackson, P., Cowen, P. N. and Bird, C. C.: Immunogold-silver staining: New method of immunostaining with enhanced sensitivity. J. Histochem. Cytochem. 31; 938-944, 1983.

18. Horisberger, M. and Rosset, J.: Colloidal gold, a useful marker for transmission and scanning 
electrob microscopy. J. Histochem. Cytochem. 25; 295-305, 1977.

19. Irie, S., Sezak, M. and Yoshihiro, K.: A faithful double stain for proteins in the polyacrylamide gels with coomassie blue and silver. Anal. Biochem. 126; 350-354, 1982.

20. Kuhnl, P. and Spielmann, W.: Transferrin: Evidence for two common subtypes of the Tf C allele. Hum. Genet. 43; 91-95, 1978.

21. Kuhnl, P. and Spielmann, W.: A third common allele in the transferrin system, Tf C3, detected by isoelectric focusing. Hum. Genet. 50; 193-198, 1979.

22. Merril, G. R., Switzer, R. C. and Van Keuren, M. L.: Trace polypeptides in cellular extracts and human body fluids detected by two-dimensional electrophoresis and a highly sensitive silver stain. Proc. Natl. Acad. Sci. USA 76; 4335-4339, 1979.

23. Merril, C. R., Goldman, D., Sedman, S. and Ebert, M.: Ultrasensitive stain for proteins in polyacrylamide gels shows regional variation in cerebrospinal fluid proteins. Science 211; 1437-1438, 1981.

24. Merril, C. R.: Stains for the detection of proteins separated by electrophoretic methods. In Proceedings of 1986 meeting of the Americans Branch of the Electrophoresis Society. National Bureau of Standards, Gaithersburg, Maryland, 1986, pp. 36-65.

25. Merril, R. C. and Pratt, M.: A silver stain for the rapid quantitative detection of protein on membranes or thin layer plates. Anal. Biochem. in press.

26. Moeremans, M., Daniels, G., Van Dijck, A., Langanger, G. and DeMey, J.: Sensitive visualization of antigen-antibody reactions in dot and blot immune overlay assays with immunogold and immunogold/silver staining. J. Immunol. Meth. 74; 353-360, 1984.

27. Moeremans, M., Daniels, G. and DeMey, J.: Sensitive colloidal metal (gold or silver) staining of protein blots on nitrocellulose membranes. Anal. Biochem. 145; 315-321, 1985.

28. Oakley, B., Kirsch, D. and Morris, N.: A simplified ultrasensitive silver stain for detecting proteins in polyacrylamide gels. Anal Biochem. 105; 361-363, 1980.

29. Roth, J. and Binder, M.: Colloidal gold, ferritin and peroxidase as markers for electron microscopic double labeling lectin techniques. J. Histochem. Cytochem. 26; 163-169, 1978.

30. Roth, J., Bendagan, M. and Orci, L.: Ultrastructural localization of intracellular antigens by the use of protein A-gold complex. J. Histochem. Cytochem. 26; 1074-1081, 1978.

31. Sammons, D., Adams, L. and Nishizawa, E.: Ultrasensitive silver-based color staining of polypeptides in polyacrylamide gels. Electrophoresis 2; 135-141, 1981.

32. Schleicher, M. and Watterson, D. M.: Analysis of differences between coomassie blue stain and silver stain procedures in polyacrylamide gels: Conditions for the detection of calmodulin and troponin C. Anal. Biochem. 131; 312-317, 1983.

33. Stibler, H., Beckman, G. and Sikstrom, C.: Subtypes of transferrin C. Hum. Hered. 29; 320-324, 1979.

34. Switzer, R. C., Merril, C. R. and Shifrin, S.: A highly sensitive silver stain for detecting proteins and peptides in polyacrylamide gels. Anal. Biochem. 98; 231-237, 1979.

35. Thymann, M.: Identification of a new serum protein polymorphism as transferrin. Hum. Genet. 43; 225-229, 1978.

36. Van Eijk, H. G., Van Noort, W. L., Kroos, M. J. and Van der Heul, C.: The heterogeneity of human serum transferrin and human transferrin preparations on isoelectric focusing gels; no functional difference of the fractions in vitro. Clin. Chim. Acta 121, 209-216, 1982.

37. Vesterberg, O. and Gramstrup-Christensen, B.: Sensitive silver staining of proteins after isoelectric focusing in agarose gels. Electrophoresis 5; 282-285, 1984.

38. Weidinger, S., Schwarzfischer, F. and Cleve, H.: Classification of transferrin (Tf) subtypes by isoelectric focusing. Z. Rechtsmed. 85; 255-261, 1980.

39. Willoughby, E. M. and Lambert, A.: A sensitive silver stain for proteins in agarose gels. Anal. Biochem. 130; 353-358, 1983.

40. Yuen, K. C. L., Johnson, T. K., Denell, R. E. and Consigli, R. A.: A silver-staining technique for detecting minute quantities of proteins on nitrocellulose paper: Retention of antigenicity of stained proteins. Anal. Biochem. 126; 398-402, 1982. 